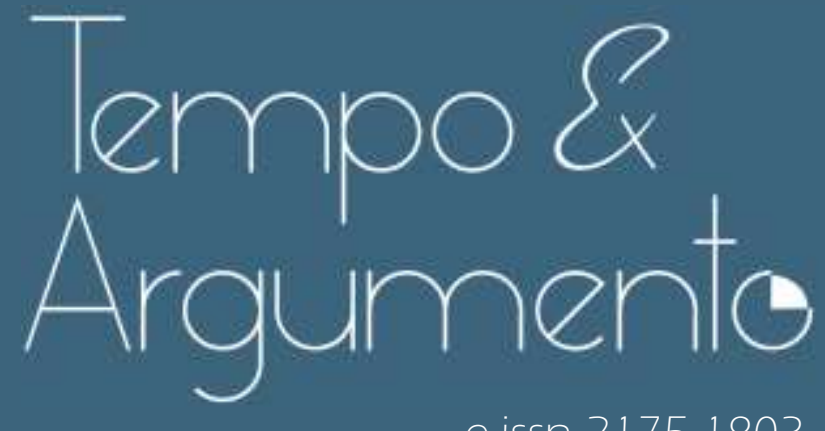

e-issn 2175-1803

\title{
O auditório da Secretaria de Saúde e Assistência Pública de Minas Gerais: lugar de memória dos trabalhadores em Belo Horizonte (1961-1964)
}

- Samuel Silva Rodrigues de Oliveira

Doutor em História, Política e Bens Culturais pela Fundação Getúlio Vargas (FGV). Professor do Centro Federal de Educação Tecnológica Celso Suckow da Fonseca (CEFET/RJ).

Rio de Janeiro, RJ - BRASIL

lattes.cnpq.br/1492578610570434

samu_oliveira@yahoo.com.br

(D) orcid.org/0000-0002-3771-9057

- Marina Mesquita Camisasca

Doutoranda em História na Universidade Federal de Minas Gerais (UFMG).

Belo Horizonte, MG - BRASIL

lattes.cnpq.br/4417429048826641

marinacamisasca@yahoo.com.br

(D) orcid.org/0000-0002-9175-5569

Para citar este artigo:

OLIVEIRA, Samuel Silva Rodrigues de; CAMISASCA, Marina Mesquita. O auditório da Secretaria de Saúde e Assistência Pública de Minas Gerais: Iugar de memória dos trabalhadores em Belo Horizonte (1961-1964). Tempo e Argumento,

Florianópolis, v. 13, n. 34, e0302, set./dez. 2021.

dof http://dx.doi.org/10.5965/2175180313342021e0302

Recebido: 19/10/2020

Aprovado: 26/05/2021 
O auditório da Secretaria de Saúde e Assistência Pública de Minas Gerais: lugar de memória dos trabalhadores em Belo Horizonte (1961-1964)

\begin{abstract}
Resumo
O artigo analisa o auditório da Secretaria de Saúde e Assistência Pública de Minas Gerais como lugar de memória dos trabalhadores. Em 1961, ele foi palco do I Congresso Nacional dos Lavradores e Trabalhadores Agrícolas e, em 1962, do I Congresso dos Trabalhadores Favelados de Belo Horizonte, sendo um dos lugares do espaço urbano identificados com o protesto social de trabalhadores. A conexão entre os dois eventos que expressavam a posição dos lavradores, trabalhadores agrícolas e trabalhadores favelados no ciclo de protestos da reforma de base, e as relações entre a reforma agrária e urbana são exploradas no artigo.
\end{abstract}

Palavras-chave: reformas de base; trabalhadores rurais e urbanos; memória social.

\title{
The auditorium of the Health and Public Assistance
} Secretary of Minas Gerais: a place of memory for workers in Belo Horizonte (1961-1964)

\begin{abstract}
The article analyzes the auditorium of the Health and Public Assistance Secretary of Minas Gerais as a place of memory for workers. In 1961, the auditorium of the Secretary of Heath hosted the 1st National Congress of Agricultural Workers and, in 1962, the 1st Congress of Favelado Workers in Belo Horizonte, being one of the places in the urban space identified with the social protest of workers. The connection between the two events that expressed the position of agricultural workers and favelados workers in the protest cycle of the basic reform, and the relationship between agrarian and urban reform are explored in the article.
\end{abstract}

Keywords: basic reform; urban and rural workers; social memory.

Os lugares de memória dos protestos de trabalhadores ${ }^{1}$ são pouco analisados pela historiografia que se dedica a estudar a história de Belo Horizonte (MG). A patrimonialização da cidade por sua vez, com as políticas constituídas

\footnotetext{
Esse trabalho situa-se em diálogo com o projeto de história pública coordenado por Paulo Fontes, no Grupo de Trabalho Mundos do Trabalho da Associação Nacional de História (ANPUH) e no Laboratório de Estudos de História dos Mundos do Trabalho (LEHMT) da Universidade Federal do Rio de Janeiro. Paulo Fontes propôs a série "Lugares de Memória dos Trabalhadores", analisando as marcas das experiências dos trabalhadores na cidade e no campo. (Disponível em: https://lehmt.org/author/paulofonteshistoriaufrjbr/).
} 
O auditório da Secretaria de Saúde e Assistência Pública de Minas Gerais: lugar de memória dos trabalhadores em Belo Horizonte (1961-1964)

Samuel Silva Rodrigues de Oliveira, Marina Mesquita Camisasca

pela prefeitura e pelo governo do estado, faz referência à memória das elites que fundaram a nova capital de Minas Gerais a partir de um projeto de modernização social. São tombados os edifícios em estilo eclético e modernista, e prevalece a narrativa cristalizada por Abílio Barreto, que contrapunha o "novo" ao "velho" na construção da capital mineira². Há pouca ênfase aos embates que foram constitutivos da construção da metrópole em seu processo de urbanização ao longo do século XX. As lutas sociais ganharam pouco significado nesse patrimônio, apesar da geografia urbana ter sido transformada por manifestações de trabalhadores e pelas estratégias de habitação popular e luta pelo direito à cidade.

O estabelecimento de um patrimônio cultural que exclui a luta dos trabalhadores no espaço da cidade desconsidera que Belo Horizonte foi uma das metrópoles que se tornou referência no ciclo de protestos pelas reformas de base nos anos $1960^{3}$. O centro urbano foi tomado por inúmeras manifestações em favor das transformações das estruturas sociais e econômicas do país, propostas pelo projeto político nacionalista que unia as esquerdas comunistas, trabalhistas e católicas. Um dos lugares centrais para tais manifestações foi o então auditório da Secretaria de Saúde e Assistência Pública. O local, que desde 1982 abriga o Minascentro (um centro de convenções), foi palco de dois congressos centrais para a campanha pelas reformas de base: o I Congresso Nacional dos Lavradores e Trabalhadores Agrícolas e o I Congresso dos Trabalhadores Favelados de Belo Horizonte.

Esses dois eventos e as suas conexões são pouco estudados pela história social e política. O presente artigo procura preencher essa lacuna, ao analisá-los em conexão, pensando o auditório como um lugar de memória. Para isso, faz uso de reportagens veiculadas pela imprensa, além de documentos produzidos e

\footnotetext{
2 Abílio Barreto (1883-1957) foi um historiador do início do século XX que escreveu a obra de referência Belo Horizonte: memória histórica e descritiva (1928), sendo um dos fundadores do Museu Histórico de Belo Horizonte nos anos 1930 e 1940. Tinha uma visão metódica da história e elaborou uma história oficial de Belo Horizonte contrapondo a modernidade "nova capital" ao "antigo" Arraial Curral Del Rey, priorizando as fontes oficiais.

${ }^{3}$ As reformas de base reuniam um conjunto de reformas: bancária, fiscal, urbana, administrativa, agrária e universitária. Sustentava-se ainda a necessidade de estender o direito de voto aos analfabetos e às patentes subalternas das forças armadas, e, também, a defesa de medidas nacionalistas prevendo uma intervenção mais ampla do Estado na economia.
} 
apreendidos pela polícia política mineira, e constrói uma argumentação que evidencia a importância desses eventos na construção da memória no espaço urbano de Belo Horizonte.

O estudo compreende que os atos de lembrar e esquecer, típicos da memória, situam-se em relações de poder. Já na primeira metade do século XX, na obra A memória coletiva, Halbwachs elabora as representações coletivas, as recordações involuntárias e as lembranças voluntárias do passado como partes de um quadro de referências simbólicas estruturado nas relações sociais. O autor traça uma investigação que afasta a memória do terreno subjetivo da consciência individual e psicológica e a identifica com a coletividade em que foi vivenciada4. Posteriormente, nos anos 1970 e 1980, a memória coletiva foi evidenciada como construção social e política, associada aos fenômenos de poder e às disputas entre os grupos reconhecendo suas experiências nas comunidades nacionais ${ }^{5}$. A coletânea em três volumes Les lieux de Mémoire, publicada entre 1984 e 1992, inseriu-se nessa configuração e esboçou um programa de investigação que problematizou a memória social, e ganhou destaque por inspirar outras pesquisas fora da França, sendo uma referência rapidamente incorporada pela historiografia brasileira (DOSSE; DELLACROIX; GARCIA, 2012; NORA, 1984).

De acordo com Pierre Nora, o organizador da coletânea francesa, os lugares de memória são, antes de tudo, restos que "nascem e vivem do sentimento que não há memória espontânea, que é preciso criar arquivos, que é preciso manter aniversários, organizar celebrações, pronunciar elogios fúnebres, notariar atas, porque essas operações não são naturais” (NORA, 2013, p. 13). Se os homens fossem capazes de viver verdadeiramente as lembranças evocadas pelos lugares, esses seriam inúteis. É preciso, assim, criar lugares de memória para que se defenda a memória ameaçada de desaparecer. O edifício da Secretaria de Saúde e Assistência Pública pode ser pensado, dessa forma, como

\footnotetext{
${ }^{4}$ As reflexões de Halbwachs foram publicadas na década de 1920, em diálogo com a sociologia de Emile Durkhein, e tornaram-se referência no livro que reuniu seus textos e artigos em 1950, cinco anos após sua morte em um campo de concentração. (HALBWACHS, 2013).

5 Nos anos 1970 e 1980, os trabalhos de Michael Pollack e Alessandro Portelli recuperaram a noção de memória coletiva, a partir da ênfase nas relações de poder. (POLLACK, 1989, 1991; PORTELI, 2005).
} 
um lugar de memória dos trabalhadores, já que esses transformaram o espaço em lócus de suas manifestações políticas em Belo Horizonte.

Na profusão de lugares de memória na contemporaneidade, com a aceleração do tempo e a intensificação da mundialização das relações econômicas, sociais e políticas, as experiências dos trabalhadores e de suas lutas nem sempre são vistas como parte das políticas de patrimônio e de memória. A criação do Minascentro, no local que abrigava a Secretaria de Saúde e Assistência Pública, e sua designação como "Centro de Convenções Israel Pinheiro da Silva" evidencia esse processo de silenciamento. Em 1971, durante o mandato de Israel Pinheiro ${ }^{6}$, em meio a grandes obras públicas na conjuntura do "milagre econômico", o governo do Estado projetou um centro de convenções no Parque da Gameleira, mas esse desabou gerando a morte de cerca de 64 operários. Na década de 1980, no curso da redemocratização do país e ascensão dos movimentos de trabalhadores, o governo de Francelino Pereira ${ }^{7}$ recuperou 0 projeto de um centro de convenções e argumentou pela criação do mesmo no edifício da Secretaria de Saúde como forma de revitalizar o centro urbano e dinamizar a economia da cidade e do estado; mas também de apagar a memória operária (SOARES; SOUZA, 2007).

Os anos 1980 e 1990, período marcado pela crise econômica e, posterior, "desindustrialização" da economia brasileira e da ascensão do programa social e político do "neoliberalismo", contribuíram para ofuscar os lugares de memória da luta dos trabalhadores na história nacional. Este artigo situa-se de forma crítica a esse cenário e investiga as relações dos trabalhadores com o auditório da Secretaria de Saúde e Assistência Pública no ciclo de manifestações pelas reformas de base.

É importante lembrar que esse auditório não foi utilizado apenas para as manifestações pelas reformas de base ocorridas no início da década de 1960. 0 edifício foi construído entre as décadas de 1920 e 1930, com projeto assinado pelos arquitetos Arquimedes Memória e Francisque Couchet, em estilo eclético.

\footnotetext{
${ }^{6}$ Israel Pinheiro da Silva (1896-1973) esteve envolvido em diferentes projetos de desenvolvimento e industrialização do estado e governou Minas Gerais entre 1966 e 1971.

Francelino Pereira dos Santos (1921-2017) governou o estado entre 1979 e 1983, sendo indicado pelo partido da Aliança Nacional Renovadora (ARENA).
} 
O local deveria acolher o externato do Ginásio Mineiro, mas acabou abrigando a Escola de Aperfeiçoamento, dirigida pela pedagoga Helena Antipoff, e, em 1948, passou a ser a sede da Secretaria de Saúde e Assistência Pública (SOARES; SOUZA, 2007). Tinha uma localização especial na geografia urbana da cidade: estava localizado nas proximidades do Mercado Central e da Praça Raul Soares, espaços de circulação e usos populares. Situado na área central de Belo Horizonte, o auditório da Secretaria de Saúde e Assistência Pública foi utilizado em diferentes contextos para reuniões sindicais e de trabalhadores.

No ciclo de protestos pelas reformas de base, o auditório foi acionado em diferentes situações de manifestações públicas. Conforme afirmado anteriormente, dois importantes eventos marcaram a relação desse edifício com a história dos trabalhadores: o I Congresso Nacional dos Lavradores e Trabalhadores Agrícolas e o I Congresso dos Trabalhadores Favelados.

Belo Horizonte era considerada um dos principais palcos para várias manifestações de trabalhadores, sendo esses dois eventos centrais para os protestos do período. No início de 1964, também estavam planejados para acontecer no mesmo auditório o congresso para criação da Central Única dos Trabalhadores da América Latina (CUTAL) entre 24 e 28 de janeiro, a manifestação de Leonel Brizola e da Frente de Mobilização Popular (FMP) em 26 de fevereiro; no centro de Belo Horizonte, e, também, estava agendado um comício de João Goulart em defesa das reformas de base em 21 de abril - data comemorativa da Inconfidência Mineira. Contudo, todos esses eventos foram impedidos de acontecer pela mobilização anticomunista que uniu a direita contra a esquerda trabalhista e comunista (MOTTA, 2002; STARLING, 1986).

O espaço da Secretaria fez parte de um processo de ascensão da classe trabalhadora no espaço público ${ }^{8}$. Essas manifestações vinculavam-se à expansão dos direitos políticos e civis no momento de redemocratização experimentado pelo país a partir de 1945 e, também, à urbanização e à crescente participação

\footnotetext{
${ }^{8}$ O espaço público é entendido por Hanna Arendt como um local no qual a ação e o discurso de cada um podem ser vistos e reconhecidos como algo dotado de sentido e eficácia para a construção de uma história comum. Segundo a autora, o espaço público difere-se do privado por ser o local da confluência da palavra e do agir humano em direção ao senso comum. Ele é por excelência o espaço de relações políticas, lugar onde se reúnem as pessoas e onde se estabelece a ação política. (ARENDT, 1983).
} 
O auditório da Secretaria de Saúde e Assistência Pública de Minas Gerais: lugar de memória dos trabalhadores em Belo Horizonte (1961-1964)

Samuel Silva Rodrigues de Oliveira, Marina Mesquita Camisasca

dos trabalhadores urbanos e rurais na vida política do país. Nesse período, houve um aumento do número de organizações vinculadas às classes trabalhadoras e identificadas ao "popular", que promoveram intensos debates sobre melhorias sociais, políticas e econômicas a serem conquistadas. No centro de Belo Horizonte, a Praça Sete de Setembro, o auditório da Secretaria de Saúde e Assistência Pública, as escadarias da Igreja São José, a Praça Rui Barbosa, a Praça Rio Branco e a Feira Permanente de Amostras - espaço onde era comemorado o 1 o de maio - tornaram-se palcos de manifestações dos trabalhadores urbanos e rurais, e dos protestos políticos ocorridos no período de 1945 a 1964.

O golpe civil-militar de 1964 restringiu o espaço de atuação dos trabalhadores, interveio em sindicatos e associações civis que representavam os trabalhadores urbanos e rurais, perseguiu lideranças políticas, cassou mandatos de representantes de trabalhadores nos órgãos legislativos e proibiu greves e outras manifestações no espaço público. Todavia, durante o período da ditadura (1964-1985)9 , os trabalhadores resistiram e o centro urbano de Belo Horizonte voltou a ser ocupado em manifestações públicas. Em 1968, o auditório da Secretaria de Saúde e Assistência foi palco para a concentração de trabalhadores contra o "arrocho salarial", ocorrida em março e nas comemorações do Primeiro de Maio, em meio às manifestações operárias, às greves e às manifestações estudantis (DELLAMORE, 2019).

Os dois eventos aqui analisados aconteceram no governo João Goulart (1961-1964), momento em que os movimentos sociais ganharam maior força e ocuparam espaços que os propiciaram reivindicar melhorias na qualidade de vida e de trabalho. A cidadania restrita instituída nos anos 1940, que destinava direitos sociais apenas aos trabalhadores urbanos com vínculo empregatício de "carteira assinada" e limitava o sufrágio aos alfabetizados, foi contestada pelos

\footnotetext{
${ }^{9}$ O termo mais adequado para caracterizar a segunda ditadura brasileira gera polêmicas entre os historiadores. Marcos Napolitano considera que ela foi militar, já que o controle do Estado e as tomadas de decisões durante os 21 anos que vigorou eram exercidos somente por lideranças militares. Isso não significa ignorar o apoio e a participação de setores da sociedade civil ao regime. Já Daniel Aarão Reis propôs a adoção do termo ditadura civil-militar para evidenciar a construção da legitimidade dos governos militares na sociedade civil e a crítica à imagem de uma sociedade inocente ou resistente à ditadura, apagando as nuances e ambivalências do comportamento social e político. (NAPOLITANO, 2014; REIS, 2014).
} 
"lavradores", "trabalhadores agrícolas" e "trabalhadores favelados". Eles exigiam a reforma agrária e urbana como garantia para o desenvolvimento nacional e para a redução das desigualdades e da exploração dos trabalhadores. São essas manifestações que serão tratadas a seguir.

\section{Congresso Nacional dos Lavradores e Trabalhadores Agrícolas e a} reforma agrária

Um dos movimentos que cresceu consideravelmente no governo Goulart foi o camponês, que em todo o Brasil ganhou força, visibilidade e reconhecimento. Neste momento, os conflitos entre latifundiários e camponeses acirravam-se, fato que impulsionou a mobilização deste último grupo. Outros fatores também contribuíram para o crescimento desse movimento, como a presença de lideranças de grupos de esquerda e da Igreja Católica no meio rural, além da atuação mais incisiva do Estado para regulamentar as relações econômicas no campo. As leis trabalhistas e sociais dos anos 1930 e 1940 regiam as relações assalariadas e formais nas cidades, sem tocar nas condições de trabalho da agricultura, pecuária e outras atividades econômicas que permaneciam na informalidade. Dessa forma, as lutas pela reforma agrária questionavam a propriedade do latifúndio e a persistência das injustiças sociais nas relações de trabalho no campo. O crescimento do movimento camponês colocava em xeque o status quo e pressionava pela realização imediata da reforma agrária.

Uma das pressões mais importantes exercidas por esse movimento ocorreu com a realização do I Congresso Nacional de Lavradores e Trabalhadores Agrícolas, que aconteceu, em Belo Horizonte, entre os dias 15 e 18 de novembro de 1961. Era feriado da Proclamação da República e uma das primeiras manifestações políticas que João Goulart participava na condição de presidente do país. A luta travada para garantir a sua posse após a renúncia de Jânio Quadros redundou na afirmação da legalidade, da democracia e da plataforma política das reformas de base na Campanha da Legalidade $^{10}$. No entanto, em meio a um

\footnotetext{
10 A Campanha da Legalidade foi um movimento social que ocorreu entre agosto e setembro de 1961. Era liderada por Leonel Brizola, governador do Rio Grande do Sul, e apoiada por
} 
acordo político para sua posse como presidente, foi adotado o parlamentarismo como forma do Congresso Nacional limitar a ação de Jango, que era acusado de ser "comunista" e de lutar pela implantação de uma "república sindical" no país.

O I Congresso Nacional de Lavradores e Trabalhadores Agrícolas, também conhecido como Congresso de Belo Horizonte, possuía dois objetivos norteadores: a obtenção de soluções para a questão agrária no Brasil; e a elaboração de um programa de reivindicações e direitos dos camponeses que expressassem um consenso para os rumos da democracia (MANIFESTO, 1961). Animava a sua realização, entre outros motivos, o entendimento de que era necessário, naquele momento de manifestação viva da nova força social, uma socialização das experiências particulares de luta, para traçar diretrizes gerais e dar unidade ao movimento camponês (COSTA, 1996). O congresso se propunha a ser um evento amplo, a congregar todas as forças interessadas em discutir questões referentes ao meio rural e seus organizadores já apontavam para esse caráter abrangente do evento:

Fazemos questão em frisar que o Congresso abraçará a todos que queiram trazer a sua colaboração para o bom êxito do Encontro. Não fazemos distinções entre participantes, sejam eles da direita, do centro ou da esquerda. A circunstância presente exige de nós uma atitude imparcial, em favor da união das forças, para que se consiga neste encontro um êxito que venha refletir diretamente em favor do homem do campo [...]. Colaboremos naquilo que nos une, deixando de lado aquilo que nos separa. (ATESTADO, 1964)

O congresso teve grande repercussão nacional e contou com a presença, além do presidente Goulart, do primeiro-ministro Tancredo Neves, do governador de Minas Gerais, José de Magalhães Pinto, e do ministro do Exterior, San Thiago Dantas. Participaram ainda vários deputados federais, intelectuais, párocos, estudantes e operários. A sua comissão organizadora era composta por: Hernani Maia - presidente; José Thiago Cintra - secretário geral; e Cândido Siqueira - tesoureiro geral. Conforme noticiou o jornal Terra Livre, o evento reuniu 1.800 delegados camponeses de todos os estados e 7.000 pessoas que se

trabalhadores, estudantes e militares. A campanha transformou Brizola em liderança nacional do trabalhismo, e colaborou para a polarização política entre esquerda e direita na década de 1960 (FERREIRA, 2005, p. 277-319). 
acotovelavam no edifício da Secretaria de Saúde e Assistência Pública, cedido pelo governo estadual (JAMBO, 1961, p. 1).

A escolha do estado de Minas Gerais para sediar o evento não foi aleatória, de acordo com Lyndolpho Silva, presidente da União dos Lavradores e Trabalhadores Agrícolas do Brasil (ULTAB), entidade criada em 1954 pelo PCB ${ }^{11}$,

Escolhemos Minas para a realização deste primeiro congresso porque aqui o latifúndio predomina. O congresso terá assim a repercussão que merece e será uma contribuição inestimável para o desenvolvimento da reforma agrária. Quem vê esse espetáculo - realmente inédito no Brasil - há de verificar que os camponeses só acreditam em seu próprio movimento. (CAMPONESES..., 1961, p. 3)

Para Francisco Julião, líder das Ligas Camponesas, a escolha de Minas Gerais ocorreu por duas razões:

1) A situação geográfica de Minas, Estado central, e, por isso, ponto ideal de convergência; 2) A fraqueza do movimento camponês em Minas, Estado em que existem condições excepcionais para sua expansão. Assinala sério: - A miséria do camponês mineiro só se equipara à do nordestino que é, como se sabe, das piores do mundo. (BRASIL..., 1961, p. 8)

As lideranças tanto do PCB/ULTAB quanto das Ligas Camponesas apontavam a escolha de Minas Gerais para sediar o congresso devido à grande concentração fundiária, à fraqueza da organização camponesa e à miséria existente nas áreas rurais mineiras. Entretanto, além desses fatores, a realização do congresso na capital mineira foi estimulada também pelo total apoio concedido pelo governador Magalhães Pinto.

Segundo a polícia política, os organizadores tentaram realizar o congresso no estado de São Paulo, e o governador Carvalho Pinto não concordou; tentaram, então, no estado da Guanabara, também não concordando o governador Carlos Lacerda (RELATÓRIO, 1961b). Já o governador Magalhães Pinto não só concordou com a realização do evento em seu estado, como forneceu também uma verba de um milhão de cruzeiros, além de dar comida, alojamento e transporte para os camponeses (CAMPONESES..., 1961, p. 3).

\footnotetext{
11 A ULTAB tornou-se um instrumento legal para a ação do partido no campo. Tinha como reivindicação principal a reforma agrária, que liberaria as forças produtivas no meio rural.
} 
O início do congresso foi marcado pela realização de uma missa na Igreja São José, o que revela a intenção dos organizadores em legitimar o evento frente à Igreja e por toda a sociedade. A obtenção do apoio do governo e da Igreja Católica indica a relevância política conquistada pelo movimento camponês no período. Mas revela também o desejo dessas instituições em controlarem, de alguma forma, esse movimento. A descrição da atitude de San Thiago Dantas diante das manifestações dos congressistas é exemplar do receio existente entre as autoridades. De acordo com o jornal Última Hora,

Quando chegou ao auditório da Secretaria de Saúde e Assistência, onde se realizava a sessão solene de encerramento do I Congresso Nacional dos Trabalhadores do Campo, o chanceler San Thiago Dantas teve uma expressão de surpresa: - "Isto está mais sério do que eu imaginava. Temo que isso se radicalize". (UNIÃO..., 1961, p. 12)

A presença de grande número de autoridades governamentais, convidadas para participar do evento não foi despropositada. Na ótica dos organizadores e dos camponeses, a presença de personalidades ilustres tornava o evento digno de nota na grande imprensa, além de possibilitar a comunicação entre essas autoridades e o campesinato. Era o momento em que os camponeses teriam a oportunidade de pressionar o Estado para que atendesse as suas reivindicações. Já para as autoridades, o seu comparecimento também era imprescindível, pois dessa forma poderiam saber o que estava sendo proposto pelas lideranças camponesas, o que facilitava a sua atuação junto ao grupo.

Em relação à dinâmica de funcionamento do congresso, presidido pelo deputado petebista Hernani Maia, é importante destacar que esta foi marcada pela divisão em duas instâncias bem determinadas: a tribuna, composta pelas atividades do plenário, e as comissões (RELATÓRIO, 1961a). No plenário, abria-se espaço para os discursos e depoimentos das pessoas que quisessem se manifestar. Já as comissões, que deveriam ter pelo menos um membro de cada delegação, eram responsáveis por discutir determinado tema. Existiam comissões designadas para debater as seguintes temáticas: reforma agrária; arrendamento e parceria; pequenos e médios proprietários; direito; assalariados e semi-assalariados rurais; organização das massas trabalhadoras do campo; 
reivindicações democráticas e sociais. Dos trabalhos de cada comissão deveria ser lavrada uma ata e elaborado um relatório das suas conclusões que seriam encaminhados à mesa para discussão no plenário (REGIMENTO, 1961).

A abertura de espaço no plenário para a manifestação de opiniões sobre as temáticas discutidas nem sempre foi acompanhada de apreciações concordantes a respeito do assunto. Opiniões divergentes daquelas manifestadas pelos camponeses não eram bem-vindas. O líder patronal rural, presidente da Federação das Associações Rurais do Estado de Minas Gerais (FAREM), órgão representante dos proprietários de terras, Josaphat Macedo, por exemplo, não foi bem recebido pelos ouvintes:

Durante o seu discurso foi vaiado várias vezes pelo plenário, pois, embora falando de reforma agrária, defendia a Constituição. A reforma que ele pregava não era nos moldes que os congressistas queriam daí o motivo das vaias. (RELATÓRIO, 1961b)

Já o deputado Francisco Julião, líder das Ligas Camponesas, segundo os informantes do DOPS/MG presentes no evento, teve outro tipo de recepção:

Admitimos que, de todos os oradores, durante o Congresso o mais aplaudido foi o deputado Julião, pois era sempre aplaudido de pé e um grande número aplaudia-o não com palmas, mas com gritos de "Revolução!!!! (RELATÓRIO, 1961b)

Alguns incidentes, contudo, também ocorreram durante 0 pronunciamento dos discursos no plenário. Durante a cerimônia de abertura, por exemplo, momentos após o início da fala do deputado Julião, ampolas de gás sulfídrico foram quebradas dentro do recinto, o que provocou a saída de grande número de pessoas, muitas das quais não retornaram (CONGRESSO..., 1961a, p. 6). Esse ato tinha por objetivo esvaziar o evento, porém não foi possível identificar sua autoria. Segundo o deputado Hernani Maia, os policiais seriam os responsáveis por tal atitude. Já a polícia afirma que membros da União Operária Camponesa do Brasil, movimento anticomunista, que se opôs à realização do congresso, seriam os autores do incidente (RELATÓRIO, 1961a).

Os trabalhos realizados durante o congresso revelam que as discussões giravam em torno dos problemas vivenciados pelos camponeses. Todavia, o tema 
mais discutido e que teve maior repercussão foi a questão da reforma agrária. Tanto que as palavras de ordem reforma agrária na lei ou na marra, trazidas pelas Ligas Camponesas, aglutinaram e animaram quase que unanimemente a massa congressista e boa parte dos comentaristas. Para muitos autores, esse lema, tão aclamado durante o Congresso de Belo Horizonte, se tornou o símbolo da radicalidade do evento e da vitória das propostas encaminhadas pelas Ligas, em contraposição às medidas legalistas trazidas pelo PCB (AZEVEDO, 1982; AUED, 1986; BASTOS, 1984). Porém, o significado dessas palavras deve ser repensado para que não se analise o movimento das Ligas Camponesas como o símbolo da radicalidade e o PCB como um grupo reformista que adotava medidas extremamente limitadas.

O próprio Francisco Julião, em discurso proferido durante o congresso, afirmou:

A verdade é que a Reforma Agrária tem de ser radical. Nada de pagamento em dinheiro, mas em títulos da dívida pública. Nada de preços extorsivos pelas terras desapropriadas. O preço deve ser o valor declarado para o imposto territorial. A política de colonização deve ser em favor do camponês. Isto só é possível se for feita pelo camponês. Estes devem participar ativamente dos órgãos que revisarão a política agrária nacional. (TRANSCRIÇÃO, 1961b, grifo nosso)

A partir das palavras pronunciadas pela liderança das Ligas Camponesas se percebe que a proposta do movimento era a modificação da forma de pagamento da indenização a ser concedida aos proprietários de terras, ou seja, Julião desejava que o § 16, do artigo 141 da Constituição Federal, fosse alterado. O que significava uma reforma agrária a ser instituída por meio de mecanismos legais. Em seu discurso, Julião não propunha a tomada de terras; pelo contrário, achava que os camponeses deveriam participar dos órgãos governamentais responsáveis pela realização da reforma agrária.

As palavras de ordem reforma agrária na lei ou na marra conseguiram congregar todos os camponeses na luta comum pela realização da reforma agrária, e não promoveram a radicalização das reivindicações. A partir da análise dos discursos proferidos no congresso, é possível perceber que a expressão "ou na marra” significava que se as reformas não viessem por meio da ação legal, 
O auditório da Secretaria de Saúde e Assistência Pública de Minas Gerais: lugar de memória dos trabalhadores em Belo Horizonte (1961-1964)

Samuel Silva Rodrigues de Oliveira, Marina Mesquita Camisasca

elas viriam nem que fosse através de mecanismos não institucionais. No entanto, a luta primeira seria pela realização da reforma agrária por meios legais. Um camponês interrogado, no momento da realização do congresso, sobre o significado da frase explicou:

Não tem sentido de ameaça [...]. Quem se reúne numa capital como Belo Horizonte não quer luta subversiva. Somos brasileiros que querem participar da vida nacional. Mas até agora temos sido os párias de uma terra rica. (UNIÃO..., 1961, p. 12)

Nota-se, assim, que as resoluções apresentadas no I Congresso Nacional de Lavradores e Trabalhadores Agrícolas expressavam essa política legal, proposta tanto pelas Ligas Camponesas quanto pelo PCB, sendo as principais delas:

a imediata modificação pelo Congresso Nacional do artigo 141 da Constituição Federal, em seu parágrafo 16, que estabelece a exigência de "indenização prévia, justa e em dinheiro" para os casos de desapropriação de terra por interesse social, o levantamento cadastral de todas as propriedades de área superior a 500 hectares e de seu aproveitamento e a desapropriação pelo governo federal, das terras não aproveitadas com área superior a 500 hectares, a partir das regiões mais populosas, das proximidades dos grandes centros urbanos, das principais vias de comunicação e reservas de água. (TRANSCRIÇÃO, 1961a) ${ }^{12}$

O documento contendo as resoluções do congresso ficou conhecido como "Declaração de Belo Horizonte”. Apesar do caráter legalista das medidas apresentadas, é importante ressaltar que, esse evento também foi marcado por algumas divergências entre as propostas do PCB/ULTAB e das Ligas Camponesas. A principal delas se referia à questão da regulamentação dos contratos de arrendamento e parceria ${ }^{13}$. No resultado aprovado pela comissão responsável pelo tema, prevaleceu a posição das Ligas Camponesas, de propor a extinção,

\footnotetext{
12 Todas as resoluções do congresso foram transcritas em relatório policial produzido pelo DOPS/MG. (APM. DOPS. Pasta 0159).

${ }^{13} \mathrm{O}$ arrendamento rural é o contrato agrário pelo qual uma pessoa se obriga a ceder à outra, por tempo determinado ou não, o uso e gozo de imóvel rural ou partes do mesmo, incluindo ou não outros bens, benfeitorias ou facilidades, com o objetivo de nele ser exercida atividade de exploração agrícola, pecuária, agroindustrial, extrativa ou mista, mediante o pagamento de certa quantia. A parceria no campo é uma modalidade contratual pela qual o proprietário cede ao trabalhador-produtor o uso da terra, partilhando com este os riscos do caso fortuito e da força maior e os frutos do produto da colheita ou da venda. As proporções da partilha variam de acordo com o contrato de estabelecido entre as partes.
} 
por lei do Congresso Nacional, de todas as formas de arrendamento ou parceria e a distribuição das terras arrendadas aos arrendatários. Entretanto, o tema não constou na “Declaração de Belo Horizonte" (ORTEGA, 1999, p. 85-86).

Após o encerramento do evento, Francisco Julião, escolhido seu orador oficial, juntamente com outros dirigentes, foram a Brasília entregar a declaração e discutir seus pontos principais com o presidente João Goulart (CORRESPONDÊNCIA, 1961). O que se percebe é que após a realização do Congresso, o governo federal passou a acelerar o processo de incentivo à sindicalização rural, além de impulsionar a criação de órgãos e a implementação de projetos responsáveis pela realização da reforma agrária. Em 1962, o governo aprovou a Lei no 4.132, em 10 de setembro, regulamentando a "desapropriação por interesse social" por decreto para "promover a justa distribuição da propriedade ou condicionar seu uso ao bem estar social” (BRASIL, 1962). Era uma iniciativa para tentar limitar a propriedade privada de acordo com sua função social, tal qual previsto no artigo 147 da Constituição Federal de 1946. Essa legislação foi seguida da Lei Delegada no 11, de 11 de outubro do mesmo ano, que criou a Superintendência de Política Agrária (SUPRA), órgão responsável, dentre outras atribuições, por executar a reforma agrária no país.

O Congresso de Belo Horizonte pode ser visto, assim, como o ápice da união dos camponeses, que se engajaram na luta política e acreditaram que promoveriam alterações na estrutura agrária do país. A maior importância a ser atribuída ao evento foi o fato de ter se constituído como o momento de consolidação do campesinato no espaço público. Os jornais da época marcaram um antes e depois do Congresso de Belo Horizonte, construindo uma temporalidade para a luta camponesa que se definia pela importância do evento. O jornal Binômio, por exemplo, dias após a realização do congresso, já anunciava as conquistas obtidas pelo movimento camponês:

Para os observadores do I Congresso Nacional de Reforma Agrária o movimento camponês passou a ser dividido em duas fases. A primeira, a de fundação de associações de trabalhadores rurais, dos modos mais diversos, com características diferentes em cada região do país, representando as necessidades imediatas da solução de problemas locais, antes do congresso; a segunda, posterior ao congresso, com uma planificação, entrosamento e 
união das ligas camponesas, associações de assalariados, posseiros e entidades representativas dos pequenos proprietários. (CONGRESSO..., 1961b, p. 6)

Os redatores do jornal Última Hora também apontavam para o caráter unificador alcançado pelo movimento camponês a partir da realização do congresso:

Além de constituir o primeiro grande lance da luta pela reforma agrária, o primeiro Congresso Nacional dos Trabalhadores do Campo teve ainda um outro aspecto: serviu para unificar o pensamento de um grupo que põe na reforma agrária o próprio sentido de luta pela independência econômica do Brasil. (UNIÃO..., 1961, p. 12)

Isso mostra como o Congresso de Belo Horizonte foi fundamental para a estruturação do movimento camponês, tanto no sentido de promover a sua reunião quanto de tornar públicos os seus interesses ${ }^{14}$. O encontro teve, assim, por efeito principal, dar uma nova dinâmica à luta camponesa, mostrando a importância da reforma agrária e o significado dessa bandeira para o movimento (MEDEIROS, 1982, p. 55). As lutas urbanas também foram movimentadas pelo evento, como abordaremos a seguir na dinâmica da ação política dos trabalhadores favelados.

\section{Congresso dos Trabalhadores Favelados e a reforma urbana em Belo Horizonte}

O I Congresso dos Trabalhadores Favelados foi organizado pelo movimento de favelas de Belo Horizonte. No ciclo de protestos das reformas de base, o movimento social estabeleceu campanhas pelo direito de moradia e reforma urbana através da Federação dos Trabalhadores Favelados de Belo Horizonte (FTFBH). Representando a "união dos favelados" - bordão repetido por lideranças em diferentes contextos e campanhas articuladas no espaço público -, a federação chegou a unir 59 associações de moradores numa pauta de reivindicações plural e multifacetada. Elas se reconheciam publicamente como

\footnotetext{
${ }^{14}$ É importante ressaltar que nem todos os que trabalhavam no campo aderiram ao movimento. O Congresso de Belo Horizonte foi fundamental para os camponeses que estavam engajados na luta política, pois mostrou que o movimento possuía força e que a luta pela terra era algo que unia a todos.
} 
"Uniões de Defesa Coletiva" (UDCs) e se organizavam nos espaços de moradia e lazer para reivindicar melhoramentos urbanos, e representavam os trabalhadores favelados junto às autoridades públicas contra as remoções e na luta pelo "direito de morar" (FEDERAÇÃO, 1959; OLIVEIRA, 2010).

O congresso ocorreu entre os dias 28 e 29 de abril de 1962, como parte das lutas dos trabalhadores nas comemorações do Dia do Trabalho. O Primeiro de Maio era apropriado simbolicamente pelos trabalhadores favelados e tinha vários significados na estratégia de luta política e social. Foi organizado pelas lideranças de associações e pelos "advogados das favelas" ligados à FTFBH, juntamente com lideranças políticas, estudantis e sindicais que haviam se mobilizado em torno do congresso camponês do ano anterior - destacando-se o professor José Thiago Cintra e o petebista Hernani Maia. O congresso ocorrido em 1961 marcou a cultura política e sindical da cidade; tanto que no ano seguinte, o deputado Francisco Julião, figura-chave na luta pela reforma agrária e de grande destaque no Congresso de Lavradores e Trabalhadores Agrícolas, foi um dos convidados para as comemorações do Primeiro de Maio em Belo Horizonte, e foi ele quem proferiu os discursos de abertura e encerramento do Congresso dos Favelados na véspera do Dia do Trabalho.

O advogado da FTFBH, Fabrício Soares, e as lideranças de associações de moradores iniciaram a divulgação e organização do congresso de favelas na Confederação Nacional dos Trabalhadores da Indústria (CNTI). Na reunião com os membros da CNTI, as lideranças dos moradores de favelas solicitaram a colaboração financeira dos trabalhadores sindicalizados, divulgaram uma enquete sobre a "reforma urbana democrática", e falaram da importância da união entre os sindicatos e os favelados para a luta dos trabalhadores. Ali também anunciaram a procura das autoridades do governo estadual e municipal para apoiar a iniciativa das associações de favelas para realizarem o congresso (RELATÓRIO, 1962).

A CNTI foi um vetor de constituição de uma cultura operária crítica às limitações do corporativismo sindical. Em 1961, os trabalhadores da CNTI elegeram Clodsmidt Riani para presidir a organização. Numa aliança entre o Partido Comunista do Brasil (PCB) e o Partido Trabalhista Brasileiro (PTB), a nova 
diretoria tinha em vista a formação da Confederação Geral dos Trabalhadores (CGT), as campanhas em favor das reformas de base e a articulação de uma unidade sindical que rompesse com os limites da estrutura corporativa do sindicalismo brasileiro, que apregoava a solidariedade e a negociação entre empresariado e trabalhadores (NEVES, 1981). A procura pela ruptura da organização corporativa do sindicalismo "pelego" significou o apoio e a aproximação com o associativismo de moradores em favelas. Numa aliança que envolvia lideranças dos trabalhadores favelados, dos estudantes e dos sindicatos, esses diferentes grupos se reuniram para o debate sobre o "custo de vida", as condições sociais da vida do operário nacional e as reformas urbanas e agrária.

O movimento de favelas apresentava-se nessa aliança defendendo a pauta da expansão dos direitos sociais do trabalhador brasileiro. Em 1962, numa das primeiras notícias veiculadas pelo jornal Diário da Tarde sobre a luta dos trabalhadores favelados, abordava-se o início de uma campanha das associações de moradores com "entidades sindicais e estudantis" para lutar pela regulamentação da "extensão do salário-família a todos os trabalhadores" (FAVELADOS..., 1962, p. 5). A demanda pelo abono do "salário-família", ou regulamentação do 13오 salário, foi uma luta que ganhou corpo nas greves gerais estabelecidas em 1953, e foi regulamentada no governo João Goulart, em 1962 (FERREIRA, 2011; LEAL, 2011). A campanha pelo "salário-família" foi um dos pontos centrais da comemoração do Primeiro de Maio em 1962, juntamente com a reforma agrária e a luta contra a "carestia", devido à alta dos preços dos alimentos com a alta da inflação.

As manifestações de favelas colocavam na esfera pública migrantes do meio rural, mulheres e crianças, simbolizando as famílias pobres, marginalizadas na sociedade. Juntamente com os camponeses, os trabalhadores favelados anunciavam a necessidade de expandir os direitos sociais e políticos, rompendo com a cidadania regulada e limitada. (FISCHER, 2008; SANTOS, 1979). No primeiro de maio, Francisco Nascimento, presidente da FTFBH, morador e líder da UDC da vila Senhor dos Passos, enfatizava as demandas pelo salário família e as reformas de base, em especial a agrária e a urbana, com intuito de melhorar as condições de vida no campo e na cidade (DEZ..., 1962, p. 2). 
Nas estratégias de mobilização do movimento social, era central a vinculação da imagem do favelado com a posição de trabalhador. A imagem e representação da favela era estigmatizada e fortemente atrelada à representação da "malandragem", da "marginalidade social", da condição de "indigência" da infância e das famílias pobres, e dos "rurícolas" deslocados e inadaptados ao meio urbano - classe e raça misturavam-se na construção do estigma da pobreza urbana. Ao apresentar-se como "trabalhador favelado", o movimento social se contrapunha a esse imaginário. A participação de lideranças de associações de moradores no Primeiro de Maio, junto com o presidente da Federação dos Trabalhadores Favelados no palanque formado na praça da Feira de Amostras tinha um efeito especial na luta política e simbólica.

Na crônica dos jornais de Belo Horizonte, as manifestações públicas do movimento de trabalhadores favelados deslocavam o lugar das vilas e favelas das seções dos crimes sensacionalistas para o campo da luta política e sindical presentes nas primeiras páginas da imprensa. A imagem da pobreza urbana no pós-abolição e ao longo do século XX na República era racializada e estigmatizada como classe perigosa. O movimento social se contrapunha a essa imagem através da identidade de trabalhador e reivindicava o seu reconhecimento como cidadão a partir dessa ênfase (CAMPOS, 2005; FISCHER; MATTOS; GRINBERG, 2018).

A polícia política manteve-se atenta a toda essa mobilização das favelas, pela aliança forjada com os trabalhadores e pelo fato do congresso se articular no ano eleitoral de 1962. As lideranças de associações de moradores registraram um regulamento que estabelecia as regras e as formas de apresentação no Congresso para aprovação pelo Departamento de Vigilância Social (DVS). Nele, estabelecia-se que

Regimento Interno

Art.10 - O 1o Congresso dos Trabalhadores Favelados realizar-se-á neste Capital, nos dias 28 e 29 de abril do corrente ano no salão do auditório da Secretaria de Saúde.

Art. 2o - A sessão de instalação será realizada no dia 28 no local indicado, iniciando-se às 19 horas [...]

Art. 3o - No dia 28, haverá duas reuniões ordinárias: uma das 9 horas às 12 horas, e outra de 15 às 18 horas, destinando-se ambas à discussão e votação das matérias de interesse dos trabalhadores favelados de Belo Horizonte. [...] 
Art. 8o - O plenário do Congresso será constituído de representantes das Uniões de Defesa Coletiva, devidamente credenciados pela comissão de credenciais.

1o - Cada União de Defesa Coletiva poderá inscrever como congressista os seus próprios associados, no número que desejar. 2o - Para que o favelado seja congressista, basta que seja maior de 18 anos de idade e seja membro da União de Defesa Coletiva, filiada a Federação de Trabalhadores Favelados de Belo Horizonte. Art. 9o - Haverá duas espécies de votação: a votação comum e a votação nominal. [...]

Art. 11ํ - A sessão de encerramento do Congresso, para o qual se convidarão o Sr. Presidente da Assembleia, o Sr. 1o Ministro do Estado, o Sr. Governador do Estado, o Sr. Prefeito de Belo Horizonte e representantes da Assembléia Legislativa e do poder judiciário, realizar-se-à as 20 horas do dia 29 de abril e terá caráter festivo e solene. (REGIMENTO, 1962)

Os congressos foram uma prática presente em várias lutas políticas urbanas e sindicais; eram parte da cultura operária do período. Esses eventos tinham a função de unir o grupo, demonstrar unidade numa pauta de reivindicação e dar visibilidade às demandas dos trabalhadores em bairros, vilas e favelas, sendo um repertório de ação coletiva presente nos movimentos sociais urbanos dos anos 1950, 1960 e 197015. A polícia política procurava identificar esses eventos e normatizar as formas de aparição dos conflitos de classe no espaço público. No congresso dos trabalhadores favelados, todos os representantes de fora das favelas eram taxados de "comunistas" e "agitadores", independente do vínculo político e partidário e do contexto e relação estabelecida com as associações de moradores $^{16}$. Por outro lado, o regulamento aprovado pelos trabalhadores favelados para realizar o evento afirmava que ele teria caráter "festivo" e contaria com a presença de "autoridades públicas", evitando apresentar os vínculos políticos e partidários dos participantes.

O regulamento do I Congresso dos Trabalhadores Favelados também demonstrava o interesse de regular e organizar as pautas e demandas a serem apresentadas no plenário. Era dada especial ênfase à forma como deveria ser organizada a seção anterior à "abertura”. No sábado do dia 28, na parte da tarde,

\footnotetext{
15 Para uma análise comparada dos movimentos de associações de bairro e favelas no Brasil entre 1940 e 1970 (BOSCHI, 1987; OLIVEIRA, 2018). Para os movimentos de Sociedades de Amigos de Bairros em São Paulo nos anos 50 e 60 (FONTES, 2010).

16 Os relatórios de investigação da polícia política sobre o I Congresso dos Trabalhadores Favelados de Belo Horizonte podem ser consultados em: APM. DOPS. Pasta 119.
} 
antes da abertura oficial às 19 horas, com o discurso das autoridades públicas e do convidado especial, Francisco Julião, ocorreriam sessões ordinárias que serviriam para compor um memorial a ser entregue às autoridades públicas com todas as demandas de equipamentos públicos e infraestrutura nas favelas. Era destacada a organização da mesa que seria composta e presidida por membros das Uniões de Defesa Coletiva, e as falas na assembleia em que teriam destaque os filiados às associações para apresentar as suas demandas.

Esse memorial era um dos componentes mais importantes da luta das favelas. Ali, cada representante de favela fazia suas demandas de arruamento, escada, construção de bicas de água (torneiras públicas que davam acesso à água), escolas, postos médicos, ajuda na construção de "sedes" de associações de moradores, o fim dos "exploradores de barracos" (dos aluguéis em favelas) e dos despejos coletivos, entre outras. As reivindicações eram em sua maioria dirigidas ao governo municipal e ao Departamento de Bairros e Habitações Populares (DHBP), órgão criado pela prefeitura, em 1956, para tratar da política de habitação e serviço social nas favelas, realizando o "desfavelamento" da cidade. As reivindicações ao direito de moradia feitas pelo movimento social tencionavam a regulamentação urbanística de Belo Horizonte que proibia a construção de melhoramentos urbanos e identificava a favela como espaço ilegal no tecido urbano (BELO HORIZONTE, 1956).

Ao final do Congresso de Trabalhadores Favelados, na sessão solene que contou com a presença de Francisco Julião, foi lida a "Carta de Direitos do Trabalhador Favelado", explicitando as conexões entre a luta no campo e na cidade:

Art. 3. O trabalhador favelado reivindica o direito de morar. O seu direito de morar significa o de não ser expulso do lote abandonado, onde ele fixou seu barracão humilde.

Se no campo a terra deve pertencer aos que nela trabalham na cidade o lote não pode deixar de destinar-se à moradia dos seus habitantes e nunca transformar-se em objeto de especulação, lucro e opressão. O latifúndio urbano, instituído por meia dúzia de poderosas companhias imobiliárias, acarreta pesados ônus ao poder público municipal, com os serviços de água, luz, transporte, calçamento e outros e impõe sacrifícios insuportáveis às classes pobres, que se vem expulsas para áreas cada vez mais distantes dos centros de trabalho, e ainda impedidos de ter sua casa própria, mesmo que humilde e sem conforto. (CARTA, 1962) 
A "Carta de Direitos do Trabalhador Favelado" era parte das performances articuladas no ciclo das reformas de base. Ao apresentar uma carta de direitos com artigos relativos à cidadania dos favelados e interpretações da história e compreensão da ocupação urbana, o documento era explícito quanto à necessidade de reformar a Constituição de 1946 para garantir a expansão dos direitos sociais, civis e políticos dos grupos que foram excluídos da cidadania regulada, e sancionada na década de 1940. O documento mostrava ainda as conexões entre política urbana e rural na ampliação da cultura de direitos dos trabalhadores.

O Congresso de Trabalhadores Favelados foi realizado às vésperas das eleições de 1962 e tinha em vista a disputa pela prefeitura municipal, que se daria entre José Raimundo, do Partido Trabalhista Brasileiro, José Maria Rabelo, do Partido Socialista Brasileiro, Nilton Veloso, da União Democrática Nacional, e Jorge Carone, do Partido Republicano. Os partidos, destacando-se os de esquerda, tentaram formar uma de suas bases eleitorais no movimento de favelas, sendo o documento do "Congresso dos Favelados" um dos nortes para os arranjos e programas eleitorais que seriam expostos nos comícios nas várias favelas da cidade naquele ano.

Com base nessas demandas, em 1963, o prefeito eleito realizou a desapropriação de terrenos de Antônio Luciano na zona oeste de Belo Horizonte ${ }^{17}$. O governo municipal de Jorge Carone (1963-1965) fez uso da Lei no 4132, promulgada em 1962, que definia a desapropriação por interesse social. A lei aprovada por João Goulart foi uma das balizas do debate e implementação da reforma agrária, e serviu como meio para garantir a desapropriação do "latifúndio urbano" de Antônio Luciano. Entre 1961 e 1964, o movimento de favelas organizou uma série de "invasões" / "ocupações"18 de lotes vagos na periferia de

\footnotetext{
Antonio Luciano foi deputado pelo Partido Social Democrata (PSD) e um dos maiores proprietários de terrenos urbanos da história de Belo Horizonte. Somente na região metropolitana da cidade chegou a ter, segundo sua própria estimativa, cerca de cem mil lotes. Tinha também aproximadamente mil casas alugadas, dois hotéis de três e quatro estrelas, várias áreas de estacionamento, postos de gasolina, oito aviões e 11 dos 18 cinemas da capital mineira. (ANTONIO LUCIANO PEREIRA FILHO, 2009).

18 A categoria "invasão" tem carga pejorativa na esfera pública e serve para criminalizar os movimentos de desapropriação por interesse social. Em contraponto a essa visão, o uso do termo "ocupação" rivaliza com a outra designação que reafirma o direito de propriedade sobre o interesse social do uso da propriedade.
} 
Belo Horizonte, com a justificativa de combater os "latifúndios urbanos", a especulação imobiliária e realizar a "reforma urbana".

As primeiras desapropriações por interesse social, para garantir o direito de moradia dos trabalhadores favelados, foram realizadas em Belo Horizonte após o Congresso dos Lavradores. Já em 1961, o advogado da FTFBH e lideranças de favelas mobilizaram os trabalhadores favelados para ocupar terrenos nas proximidades do bairro Santa Efigênia, em área que o deputado federal pelo Partido Social Democrata, Antônio Luciano, se dizia proprietário. O nome dado à favela criada nesse local foi "Vila Camponesa", em homenagem ao Congresso de Lavradores ocorrido na cidade (RELATÓRIO, 1961c). Esse movimento de pressão para desapropriação do "latifúndio urbano" de Antônio Luciano, em Belo Horizonte, teve continuidade durante o Congresso de Favelados e colocou o "latifúndio" como inimigo tanto dos trabalhadores rurais quanto urbanos.

A centralidade que a figura de Francisco Julião ocupou tanto no Congresso de Trabalhadores Agrícolas quanto no Congresso de Favelas é outro indício das fortes conexões entre reforma agrária e urbana. No discurso da militância de esquerda dos anos 1960, a reforma agrária seria um meio para reduzir o problema habitacional, a pobreza urbana e a alta do "custo de vida", tanto no campo quanto nas cidades.

\section{Conclusão}

A Secretaria de Saúde e Assistência Pública foi lugar central nas mobilizações dos trabalhadores na década de 1960. O edifício em estilo eclético, dialogando com o imaginário das elites que fundaram Belo Horizonte como capital do estado, ganhou usos populares depois que passou a sediar a Secretaria de Saúde, em 1948. Com a expansão dos direitos civis e políticos a partir de 1946, o auditório da secretaria tornou-se espaço para manifestações e protestos dos trabalhadores, assim como outros lugares da região central de Belo Horizonte. $O$ Congresso dos Lavradores e Trabalhadores Agrícolas e o Congresso dos Trabalhadores Favelados - eventos importantes para os movimentos camponês e de favelas - aconteceram nesse mesmo auditório, espaço que merece ser resgatado como lugar de memória da luta trabalhadora do século XX. 
Os movimentos rurais e urbanos se apropriaram desse espaço para debater pautas e apresentar reivindicações ao Estado. O local foi utilizado por esses movimentos na tentativa de dialogar com o poder público na busca de uma cidadania mais inclusiva, que permitisse a esses sujeitos, principalmente, o acesso à terra, seja no campo ou na cidade. As reformas urbana e rural foram as principais pautas debatidas nesses dois congressos e se articulavam, já que ambas defendiam o direito dos favelados e dos camponeses de conquistarem um pedaço de terra regularizado e regulamentado, que garantisse o direito à moradia digna e à sobrevivência. Contudo, a transformação da Secretaria de Saúde e Assistência em centro de convenções, na década de 1980, tentou ofuscar essa memória social do uso do espaço urbano como lócus da manifestação política dos trabalhadores urbanos e rurais, que foi intensa no início da década de 1960.

\section{Referências}

ANTONIO LUCIANO PEREIRA FILHO. In: CPDOC. Rio de JaneirO: FGV, 2009. Disponível em: http://www.fgv.br/cpdoc/acervo/dicionarios/verbetebiografico/pereira-filho-antonio-luciano. Acesso em: 19 mar 2021.

ARENDT, Hannah. A condição humana. 2. ed. Rio de Janeiro: Forense Universitária, 1983.

ATESTADO produzido pela polícia sobre documentação apreendida na residência de Élson Costa. Contém transcrição de documento produzido pelos organizadores do I Congresso Nacional de Lavradores e Trabalhadores Agrícolas. [Belo Horizonte: DOPS], 10 jun. 1964. Arquivo Público Mineiro. Fundo DOPS. Pasta 5069.

BELO HORIZONTE. Lei $n^{\circ} 572$ de 1956, 12 de setembro de 1956. Altera as multas impostas por infração ao regulamento de construções quando houver exploração de favelas e dá outras providências. [Belo Horizonte: Câmara Municipal], 1956. Disponível em: https://cm-belohorizonte.jusbrasil.com.br/legislacao/238615/lei-572-56. Acesso em: 16 jun. 2020.

BORGES, Maria Eliza Linhares. Estilistas urbanos do universo rural: o PCB na luta pela sindicalização rural em MG. Revista Brasileira de História, São Paulo, n. 27, p. 73-86, 1994. 
BOSCHI, Renato Raul. A arte da associação: política de base e democracia no Brasil. São Paulo: Vértice, 1987.

BRASIL às vésperas da revolução, Binômio, [S.l.], 30 out. 1961, p. 8. Acervo José Maria Rabelo.

BRASIL. Lei 4.132, de 10 de setembro de 1962. Define os casos de desapropriação por interesse social e dispõe sobre sua aplicação. [Brasília: Presidência da República, 1962]. Disponível em: http://www.planalto.gov.br/ccivil 03/leis/l4132.htm\#: :text=Define\%20os\%20cas os\%20de\%20desapropria\%C3\%A7\%C3\%A3o,Art. Acesso em: 20 jun. 2020.

CAMISASCA, Marina Mesquita. Camponeses mineiros em cena: mobilização, disputas e confrontos (1961-1964). 2009. Dissertação (Mestrado em História) - Faculdade de Filosofia e Ciências Humanas, Universidade Federal de Minas Gerais, Belo Horizonte, 2009.

CAMPONESES em BH: "Reforma Agrária já ou revolução”, última Hora, [S.l.], 15 nov. 1961 a, p. 3. Hemeroteca Histórica - Biblioteca Estadual Luiz de Bessa.

CAMPOS, Andrelino. Do quilombo à favela: a produção do "espaço criminalizado" no Rio de Janeiro. Rio de Janeiro: Bertrand Brasil, 2005.

CARTA de Direitos do Trabalhador Favelado. [S.L.], 29 mar. 1962. Arquivo Público Mineiro. Fundo DOPS. Pasta 0119.

CONGRESSO de Lavradores iniciou ontem, Estado de Minas, [S.l.], p. 6, 17 nov. 1961a. Hemeroteca Histórica - Biblioteca Estadual Luiz de Bessa.

CONGRESSO marcou nova fase no movimento camponês, Binômio, [S.l.], p. 620 nov. 1961b. Acervo José Maria Rabelo.

CORRESPONDÊNCIA policial enviada ao chefe do DOPS-MG, Alberto de Sales Fonseca Júnior, pelo agente no 1896 que estava infiltrado no I Congresso Nacional de Lavradores e Trabalhadores Agrícolas. [Belo Horizonte: DOPS], 18 nov. 1961. Arquivo Público Mineiro. Fundo DOPS. Pasta 0294.

COSTA, Luiz Flávio Carvalho. Sindicalismo rural brasileiro em construção. Rio de Janeiro: Forense Universitária: UFRRJ, 1996.

DELLAMORE, Caroline. Forjando lideranças: comportamentos políticos e atuação no Sindicato dos Metalúrgicos de Belo Horizonte e Contagem durante a ditadura militar brasileira (1964-1985). 2019. Tese (Doutorado em História) Faculdade de Filosofia e Ciências Humanas, Universidade Federal de Minas Gerais, Belo Horizonte, 2019. 
DEZ mil pessoas em praça pública comemoram o Dia do Trabalhador, Diário da Tarde, [S.l.], p. 2, 01 maio 1962. Hemeroteca Histórica - Biblioteca Estadual Luiz de Bessa.

DOSSE, François, DELACROIX, Cristhian, GARCIA, Patrick. Correntes historiográficas na França: séculos XIX e XX. Rio de Janeiro: FGV, 2012.

FAVELADOS querem salário-família para o trabalhador, Diário da Tarde, [S.l.], , p. 511 jan. 1962. Hemeroteca Histórica - Biblioteca Estadual Luiz de Bessa.

FEDERAÇÃO DOS TRABALHADORES FAVELADOS DE BELO HORIZONTE. Estatuto da Federação dos Trabalhadores Favelados de Belo Horizonte, 27 jan. 1960. Cartório Gero Olíva.

FERREIRA, Jorge. João Goulart: uma biografia. Rio de Janeiro: Civilização Brasileira, 2011.

FERREIRA, Jorge. O imaginário trabalhista: getulismo, PTB e cultura política popular (1945-1964). Rio de Janeiro: Civilização Brasileira, 2004.

FISCHER, Brodwyn, MATTOS, Hebe; GRINBERG, Keila. Direito, Silêncio e racialização das desigualdades na História Afro-Brasileira. In: ANDREWS, George, LA FUENTES, Alejandro (org.). Estudos Afro-latino-americanos, uma introdução. Cidade de Buenos Aires: CLACSO, 2018. p.163-215.

FISCHER, Brodwyn. A poverty rights: citizenship and inequality in TwentiethCentury Rio de Janeiro. Standford: Standford University Press, 2008.

FONTES, Paulo. Um nordeste em São Paulo: trabalhadores migrantes em São Miguel. Rio de Janeiro: FGV, 2010.

HALBWACHS, Maurice. A memória coletiva. 2. ed. São Paulo: Centauro, 2013.

JAMBO, Sosthenes. Uma nova etapa no processo revolucionário brasileiro, Terra Livre, [S.l.], p. 1, nov. 1961. Hemeroteca luta pela terra. Disponível em:

http://docvirt.com/Hotpage/Hotpage.aspx?bib=HEMEROLT\&pagfis=13250\&url=htt p://docvirt.com/docreader.net\#. Acesso em: 08 out. 2020.

LEAL, Murilo. A reinvenção da classe trabalhadora (1953-1964). Campinas: Unicamp, 2011.

MANIFESTO de convocação para a participação no I Congresso Nacional de Lavradores e Trabalhadores Agrícolas. Belo Horizonte, 20 maio 1961. Arquivo Público Mineiro. Fundo DOPS. Pasta 0111.

MEDEIROS, Leonilde Servolo de. A questão da reforma agrária no Brasil 19551964. 1982. Dissertação (Mestrado em Ciência Política) - Universidade de São Paulo, Programa de Pós-Graduação em Ciência Política, São Paulo, 1982. 
MOTTA, Rodrigo Patto Sá. Em guarda contra o "perigo vermelho": o anticomunismo no Brasil (1917-1964). São Paulo: Perspectiva; Fapesp, 2002.

NAPOLITANO, Marcos. 1964: história do regime militar brasileiro. São Paulo: Contexto, 2014.

NEVES, Lucília de Almeida. CGT no Brasil (1960-1961). Belo Horizonte: Vega, 1981.

NORA, Pierre. Entre Memória e História: a problemática dos lugares. Projeto História, São Paulo, n. 10, p.7-28, dez. 1993.

NORA, Pierre (org.). Les Lieux de memoire. Paris: Gallimard, 1984.

OLIVEIRA, Samuel Silva Rodrigues de. Associativismo de trabalhadores favelados no Rio de Janeiro e em Belo Horizonte (1954-1964). Estudos Históricos, Rio de Janeiro, v. 31, n. 65, p. 349-368, set./dez. 2018.

OLIVEIRA, Samuel Silva Rodrigues de. O movimento de favelas de Belo Horizonte. 1. ed. Rio de Janeiro: e-papers, 2010.

ORTEGA, Any Marise. As esquerdas, a questão agrária e os caminhos da revolução brasileira no "Congresso Camponês" de Belo Horizonte de 1961. 1999. Dissertação (Mestrado em Ciências Sociais) - Pontifícia Universidade Católica de São Paulo, São Paulo, 1999.

POLLACK, Michael. Memória, esquecimento e silencio. Estudos Históricos, Rio de Janeiro, v. 2, n. 3, p. 3-15, 1989.

POLLACK, Michael. Memória e Identidade social. Estudos Históricos, Rio de Janeiro, v. 5, n. 10, p. 200-212, 1992.

PORTELI, Alessandro. O massacre de Civitella Val di Chiana (Toscana: 29 de junho de 1944). In: FERREIRA, Marieta; AMADO, Janaina. Usos e abusos da história oral. Rio de Janeiro: FGV, 2005, p. 103-130.

REGIMENTO Interno do I Congresso Nacional de Lavradores e Trabalhadores Agrícolas. Belo Horizonte, 15 set. 1961. Arquivo Público Mineiro. Fundo DOPS. Pasta 0159.

REGIMENTO Interno do I Congresso dos Trabalhadores Favelados. Belo Horizonte, 29 mar. 1962. Arquivo Público Mineiro. Fundo DOPS. Pasta 0119.

REIS, Daniel Aarão. Ditadura e democracia no Brasil. Rio de Janeiro: Zahar, 2014.

RELATÓRIO policial sobre o I Congresso Nacional de Lavradores e Trabalhadores Agrícolas. Belo Horizonte, 20 nov. 1961a. Arquivo Público Mineiro. Fundo DOPS. Pasta 0159. 
RELATÓRIO policial sobre o I Congresso Nacional de Lavradores e Trabalhadores Agrícolas. Belo Horizonte, 20 nov. 1961b. Arquivo Público Mineiro. Fundo DOPS. Pasta 0278

RELATÓRIO de Investigadores. Belo Horizonte, 23 nov. 1961c. Arquivo Público Mineiro. Fundo DOPS. Pasta 0119.

RELATÓRIO de Investigação do agente no1896. Belo Horizonte, 14 fev. 1962. Arquivo Público Mineiro. Fundo DOPS. Pasta 0119.

SANTOS, Vanderlei Guilherme dos. Cidadania e justiça: a política social na ordem brasileira. Rio de Janeiro: Campus, 1979.

SOARES, Carolina Pereira, SOUZA, Françoise Jean de O. Centro Mineiro de Promoções Israel Pinheiro - MinasCentro (Processo no 01-058164-07-10). Belo Horizonte: PBH: Conselho Deliberativo do Patrimônio Cultural de Belo Horizonte: Gerência de Patrimônio Histórico, 2007.

STARLING, Heloísa Maria Murgel. Os senhores das gerais: os novos inconfidentes e o Golpe de 1964. 3. ed. Petrópolis: Vozes, 1986.

TRANSCRIÇÃO das resoluções do I Congresso Nacional dos Lavradores e Trabalhadores Agrícolas contidas em relatório policial. Belo Horizonte, 20 nov. 1961a. Arquivo Público Mineiro. Fundo DOPS. Pasta 0159.

TRANSCRIÇÃO de discurso de Francisco Julião proferido durante a realização do I Congresso Nacional de Lavradores e Trabalhadores Agrícolas. Belo Horizonte, 17 nov. 1961b. Arquivo Público Mineiro. Fundo DOPS. Pasta 0159.

UNIÃO pela reforma agrária surpreendeu, Última Hora, [S.l.], p. 12, 20 nov. 1961. Hemeroteca Histórica - Biblioteca Estadual Luiz de Bessa.

Universidade do Estado de Santa Catarina - UDESC

Programa de Pós-Graduação em História - PPGH

Revista Tempo e Argumento Volume 13 - Número 34 - Ano 2021 tempoeargumento.faed@udesc.br 